\title{
Leadership Spirituality in Banking Professionals and Its Impact
}

\section{on Organizational Commitment}

\author{
Ali Usman \\ University of the Punjab Gujranwala Campus, Pakistan \\ E-mail: usamaz_07@hotmail.com \\ Rizwan Qaiser Danish \\ Chairman Department of Busines \\ University of the Punjab Gujranwala Campus, Pakistan \\ E-mail: rdanish2000@yahoo.co.uk
}

\begin{abstract}
Spirituality has been found as the key indicator in enhancing and increasing multiple levels of organizational success and accomplishment. The present study explores the relationship between the spirituality and Job satisfaction of 121 branch managers, area managers and regional managers of various private and public sector banks of Pakistan. For the purpose of study an independent spirituality assessment scale (iSAS) developed by Rojas (2002) was used. Spirituality is found quite significant in predicting the affective commitment among the employees. Managerial implications, Limitations and future guidelines have also been provided for future research.
\end{abstract}

Keywords: Work spirtuality, Organizational commitment, Leadership spirituality

\section{Introduction}

Work Spirituality has been proved a sanctified and blessed intangible asset for an organizational long term progress and survival. The philosophy of spirtuality prevails Gods values at working place i.e. peace, love, care, affection, interconnectedness and association which resultantly build a strong connection between employees and their organizations. The work spirtuality is a determinant of affective organizational commitment as it adjusts employee's behaviour and cognition towards work, thus creating a strong association and a sense of wholeness among them. According to Aydin and Ceylon (2009) spirituality asserts the influence on learning capabilities of employees with the prior involvement of affection, care and loyalty which not only impacts their productivity but also increases the level of organizational commitment. The spiritual values are found quite significant in upgrading employees morality, behaviour helping them in strengthening their connection with the organization. Mario, Frederick, and Geroy (2009) are of the view hat spiritual leadership promotes transcendence by the effective demonstration of affection, care and empathy towards followers and helping them in process of meaning creation which as a result develops a strong inner connection with work place making them more committed, attached and loyal with the organizations. The stronger is the spiritual culture stronger will be the affective organizational commitment.

\section{Literature Review}

The term spirituality is a religious philosophy that empowers an organization in multiple dimensions of work, intrinsic motivation and imparts delightful impact on overall organizational behavior. According to Chopra (2002), both leadership as well as spirituality have a very strong influence on organization's overall performance.Spirtuality in leadership have been one of the core issues that significantly impacts the productivity, commitment, mutual collaboration at work and job satisfaction. According to Stadler (1998), the leadership spirituality significantly associates the employee's commitment and prospect's an organizational change with optimal progression of common and shared perception and vision. Leadership and work spirituality ensures the high commitment, job satisfaction and overall organizational productivity. (Baldrige National Quality Program, 2005; Fry \& Matherly, 2006; Kaplan \& Norton, 1992, 1996, 2004) Stated that Organizational commitment, job performance, job satisfaction and high productivity endurance is an evident feature of work and leadership spirituality at organizational level. Today organizations are deliberately seeking leadership spirituality that would influence in prevailing the intrinsic motivation, inspiration, moral, ethical and altruistic values that compel an organization towards vision accomplishment. According to Manuel Castells 
(1998), global organizations in the present sophisticated and technological setup are seeking to comply with more significant and deliberate impacts of work spirituality. Where spirituality upgrades the morality and modifies the individual thinking by introducing the concept of self actualization in their lives. According to Conger (1994), it is the spirituality that actualizes our true self as it explains our emotions, explores our inner strengths and identifies what we are deep down and how much we are divinely blessed, evidently calling it as the knowledge of heart.

Where spirituality impact's on the behavior, attitude, morality and ethical wellbeing of individuals that incorporates self realization along with the job satisfaction and organizational commitment. Brandt (1996) states that the motive of work spirituality is to enlighten the individual psychology with awareness, knowledge and dissemination in relation with universal values of ethics, which eventually with an invasion of inner happiness prompts the betterment of personal and work life. As spirituality subsequently promulgates the spiritual survival that has a distinct and valuable features in various aspects of organization behavior. (Hillard, 2004), posits a view that spiritual grounds provide the roots for most of organizational activities, decisions and practices, thus stimulating a growing patterns of spiritual realm which solves our psychological ethical and moral ambiguities. Where Spiritual cause aligns the individual and organizational values for organizational success. (Duschon \& Plowman, 2005; Fry et. al., 2005; Malone \&Fry, 2003), posits a view that high productivity, stake holder's reliance and commitment endurance is an assertion of work spirituality which could be feasible only when organizational cultural values and its visionary aspects conveniently matches with employees personal potentials and spiritual connotations. Where leadership spirituality associates with loyalty, attachment, cares for work and for others at work place. According to (Power, Higgins, \& Kohlberg, 1989), leadership spirituality disseminates the followers with work ethics, norms, procedures, guidance, rules, meanings and values, creating a synergy of employees for their moral personification. Where spirituality is a collective bargaining that purposely seeks the stupendous outcomes for the organizations with unanimous rationality. (Eggert, 1998), is of the view that leadership spirituality promulgates the subordinates with rationality, nobleness, meaning accomplishment, group thinking, sociability and mutual collaboration at organizational level.

Where the leaders with traits like optimism and rationalism and high morality get more prominence in their organizations. According to (Rinpoche, 1993, p. 209), the elegance of perfunctory spiritual leader ship always benefits the organizations with subsequent altruistic and intellectual disseminations. As the spirituality owes the concept modification, manifestation and self development there by conjuring the multiple facets of job satisfaction and commitment. There is clear evidence proclaiming the significance between the various features of leadership spirituality i.e. altruistic love, aesthetics, meaning creation, wholeness, ethical, moral up gradation and individual's productive characteristics of the organizations (Fry, Vitucci, \& Cedillo, 2003; Malone \& Fry, 2003; Townsend, 1984).The more commitment is enhanced if the psychological association of employees and their organizations increases along with a significant increase in their self identity. Lilius et al (2005), states that emotional and psychological affiliation with work place is a result of employees significant and exclusive commitment and determination in their organizations. Where spirituality creates a balance between work and personal life with a splendid charm. According to (Vicari, 2003), majority of experts claim that individual's personal life and life at work is strongly influenced by the spiritual dogmas. Where spirituality has become an essential factor for the organizational survival in long run. The organizations cannot survive and retain their consistant performance in the long run, until the individual and organizational competencies are not enhanced repeatedly and if required knowledge literature, meanings, attributes, values and dissemination of spirituality are not properly diffused in the work place. (Miller in Hesselbein ,1997). Where affective commitment is significantly related to the individual personal values in relation with the values imposed by the organizations. Barrett $(1998,2003)$, posits a view that affective commitment, satisfaction and performance of individuals and of organization is infect the subsequent productive coalition of three types of values i.e. values belonging to self, to organization and work and individuals perceived values. Where spirituality modifies the individual emotional attachment with their work place irrespective of the attachment with financial gains from the organizations.

Means and measures of spirituality not only align individual and organizational vision and goals but also creates a frame work that links personal an well as work life of individuals, inspiring them to work with the deliberate intentions of organizational accomplishment rather than seeking lucrative benefits. (Miller, 1998). Orientation of spirituality in the organizational set up and culture builds strong association and affiliation of employees with organizations. Klein (2001), stated that managers should allow the wider diffusion of spiritual values in organizational culture as it will lead to employee's strong affiliation and commitment with their organizations where as narrowing down its impact leading to lower emotional association. For a greater societal impact in organizations, it requires spiritual domains to be progressed. According to (Bhindi \& Duignan, 1997; Conger, 1994; Fairholm, 1996; Rogers \& Dantley,2001; Vaill, 1998; Wheatley, 1994), For creating a reasonable balance in the working community and employees, organizations are deliberately seeking a liberalized leadership essentially for developing their organizational setup, that will merge the organizational values and vital aspects of religion and spirituality such as altruistic love, wholeness, dissemination ,procurement ,care; there by owing a multifold organizational accomplishment. Where spirituality lessens the burden of work, anxiety, pressure and individual differences, as it aids in helping the leader ship to deprive the 
pressure and other psychological dilemmas and enhances the level of productivity. According to Frew (2000), the spirituality at work not only reduces the burden and delirium but also aids in coping with the stress and pressure. It is the spirituality that catches sustainability, enhances our authenticity in long term growth and development towards our work. Klein and House (1995), stated that it is the spirituality of leader ship that resolutes the subordinates thus generating numerous, optimized and valuable outcomes with an elegance of self personification, intensified will power and strong organizational commitment. It is as though the intrinsic motivation coming out of leadership spirituality that drives individual's, devotion, determination, dedication, honesty, care and commitment towards work. (Benware \&Deci, 1984; Deci \& Ryan, 1985) posited the view leader ship spiritually imposes delightful impact on meaning creation, learning, optimal levels of productivity as well as it allocates a significant growth, development and wellbeing at work and in personal life.

In the light of above review the following hypotheses are deducted.

H1: The Intrapersonal aspect of spirituality of bank managers is positively and significantly correlated with Organizational Commitment.

H2: The Interpersonal aspect of spirituality of bank managers is positively and significantly correlated with Organizational Commitment

H3: The superapersonal aspect of spirituality of bank managers is positively and significantly correlated with Organizational Commitment

H4: The ideopraxis aspect of spirituality of bank managers is positively and significantly correlated with Organizational Commitment

H5: Spirituality has a significant and positive impact on Organizational Commitment

\section{Methodology}

The present study aims at exploring the impact of leadership spirituality on organizational commitment of banking professionals. These banking professionals include branch managers, area managers and regional managers both from public and private sector. All these banks possess centralized management and hierarchal structure, formal working conditions, transparent regulations and strong organizational culture. The managerial staff of these banks is trained on a regular basis with both managerial and operational training programs and various technical courses relating to credit, accounting and financial management. All of these banks are being regulated and controlled by the state bank of Pakistan there by showing similarity in nature of work and organization culture that resultantly formulates a homogenous population, and selecting a sample of branch managers, area managers and regional managers from the banking sector of a large city of Gujranwala can be considered as sample representing the entire population of branch managers area managers and regional managers of rest of Pakistan. For the purpose of study, a convenience sampling technique was used to record the responses of the 121 bank managers. A total of 130 questionnaires were distributed to branch managers, area managers and regional managers of various banks, out of which 121 questionnaires were returned which were completely usable at a response rate of $92 \%$.

\section{Defining Variables}

\subsection{Intrapersonal Aspect}

Intrapersonal aspect is an aspect of spirituality that enlightens the essence of inside world of individuals. There are five modes of interpersonal aspect of spirituality which include fulfillment of self, self determination, self control, discovery of self and enrichment of self. An independent spirituality assessment scale iSAS developed by Rojas (2002) was used to measure the intrapersonal aspect of spirituality. A Likert scale from 1 (strongly disagree) to 5 (strongly agree) was used to record the responses.

\subsection{Interpersonal Aspect}

Interpersonal aspect of spirituality explains spiritual relationship of an individual with other. There are four modes of interpersonal aspects of spirituality which include partnership mode, small group mode, organizational mode and movement mode. An independent spirituality assessment scale iSAS developed by Rojas (2002) was used to measure the interpersonal aspect of spirituality. A Likert scale from 1 (strongly disagree) to 5 (strongly agree) was used to record the responses.

\subsection{Superapersonal Aspect}

The superpersonal aspect of spirituality explains the effectiveness of relationship between a manager and his subordinate. There are three modes superapersonal aspect of spirituality which include transactional mode, transformational mode and transfiguration mode. An independent spirituality assessment scale iSAS developed by Rojas (2002) was used to measure the superapersonal aspect of spirituality. A Likert scale from 1 (strongly disagree) to 5 (strongly agree) was used to record the responses. 


\subsection{Ideoproxis}

The ideoproxis aspect of spirituality explains the resemblance between individual's philosophy and life as a whole. An independent spirituality assessment scale iSAS developed by Rojas (2002) containing three items, was used to measure the ideoproxis aspect of spirituality. A Likert scale from 1 (strongly disagree) to 5 (strongly agree) was used to record the responses.

\subsection{Job Satisfaction}

Job satisfaction is defined as the degree to which an individual gets feelings of fulfillment and accomplishment from the work. A Job satisfaction survey designed by Moorman (1993) comprises a ten items questionnaire derived from the Minneosota Satisfaction Questionnaire (MSQ). A Likert scale from 1 (strongly disagree) to 5 (strongly agree) was used to record the responses.

\subsection{Affective Commitment}

The affective commitment is the inner strength of relationship between individual's identity and attachment with their organizations. A six itemed organizational commitment questionnaire designed by Meyer et al. (1989) was used to measure the affective commitment. A Likert scale from 1 (strongly disagree) to 5 (strongly agree) was used to record the responses.

\section{Analysis and Results}

For the purpose of analysis, SPSS 15 software was used to analyze the coded data. Cronbach's reliability alpha for all the scales was found ranging between 0.70 to 0.89.In all of 121 respondents, 116 were males and 5 were females. Majority of the respondents about $48 \%$ belong to the age group ranging between 31-40 years. Where minimum number of respondents i.e. 10\% respondents belong to the age group between 51-60 years. The numbers of respondents who are married were 102, where as the 19 respondents were unmarried. Most of the respondents 89 (74\%) belongs to the private sector where as the rest of 32 respondents belong to public or governmental sector. About $25 \%$ of respondents have the working experience between 3-5 years, 23\% have working experience between 5-10 years and only 15 respondents have working experience of more than 10 years in their organizations.

The means and standard deviations of several modes of four aspects of spirituality are given in the table1.All four aspects of spirituality have the mean vales 3.91, 3.35, 3.57 and 3.63. Where the intrapersonal aspect of spirituality has the highest mean value $M=3.91$ which provides a strong evidence that the five modes of intrapersonal aspect of spirituality are the most overriding and major aspects of spirituality which reflects strongly committed inner side of banking professionals. Among all the various modes of spirituality the mean value of the self determination is found to be the highest $M=4.32$ having a standard deviation of 0.46 where as the mean value is found to be least in the partnership mode of the spirituality $M=3.16$ with a standard deviation of 0.66 . The high mean value of organizational commitment indicate the managers internal locus, affiliation, attachment and loyalty with their organizations.

The results in table 2 show the Pearson's Product Moment Coefficient Correlation, among aspects of spirituality and organizational commitment. All the correlations are found to be significant as there is strong positive correlation between interpersonal and interpersonal aspect of spirituality, where among all the aspects, intrapersonal aspect of spirituality is found to be more significantly correlated with organizational commitment $r=.386 p<0.01$ which enlights the patterns of manager's strong spiritual behavior, high levels of, internal locus and psychological attachment with their organizations. A little correlation exists between the ideopraxis aspect of spirituality and organizational commitment $r=.154, p<0.05$. Which means that they are quite sterio typical in nature and not very creative and innovative.

The integrity and goodness of fit can be checked through ANOVA given below in the table 3. In the table the proportion of variance in the dependent variable is measured and explained due to variation in the independent variable. Goodness of the fit can be determined through p values and is presented in the ANNOVA table below. As lesser the $p$-value the greater will be the level of confidence consequently stronger will be the goodness of fit of the model. Goodness of the fit of the model can be checked by the F value i.e. $F=7.94$ and the p value which is less than 0.01 which ensures the fitness of data in model.

In the table 4 the TSS, ESS and RSS values are found. TSS indicates the total deviation in the dependent variable (organizational commitment) and ESS indicates the deviation explained by this model. In this model the value of $\mathrm{R}$ square measures the percentage of variation in the dependent variable as a result of variation in the independent variables.R square can be found by ratio ESS/TSS and is .215. Results shows that the value of R square which shows that only $21.5 \%$ of the variation in the dependent variable is explained by the regression model.

In the table 4 , the variation in dependent variable by the model is explained. Like value of the $\mathrm{R}$ square which is $21.5 \%$ value of adjusted $\mathrm{R}$ square is $18.8 \%$ which explains that $18.8 \%$ of variance in the dependent variable is measured due 
to the variation the independent variable (organizational commitment).A total of $40.3 \%$ of variance is explained in the table. The value of standered error of estimate is found to be 3.61 which is quite significant towards results.

The table 5 explains the proportion of variance in dependent variable due to individual variables, as the reliability of individual coefficients. The "t" value and value of "sig." thus provide the confidence with which we can support the estimate. Here the p value is less than 0.01 , so we can affirm the trueness of " $\mathrm{B}$ " as it falls in confidence level of 0.95 . If the value of $\mathrm{p}$ ranges between 0.05 to 0.01 than in such condition the " $\mathrm{B}$ " is acceptable and makes it statically significant, but for any value of sig. greater than 0.01 the "B" will no longer remain significant. Where the range of individual coefficients given in the table indicates that the intrapersonal aspect falls between -0.96 to .234 , interpersonal 0.30 to .273 superapersonal 0.83 to .511 and ideopraxis -.571 to .357. All these values have a confidence level of $95 \%$.

\section{Discussion}

The current study explores the impact of Leadership spirituality on organizational commitment of branch managers, area managers and regional managers. The results show a strong and positive correlation between aspects of spirtuality and organizational commitment.Spirtuality serves as the essence for the meaning creation, altruistic love, affiliation, wholness, care, affection and develops an inner interaction of employees with others and organization, resultantly it develops an internal locus which imparts delight full effect on organizational commitment. It mostly concerns and emphasizes on the issues of individual development rather than focusing on the material issues in the organization that resultantly enhances the productivity and strong organizational attachment of employees. Among all the banking professionals, the managers with high scores posses high spiritual values and are more intrinsically motivated and ethically developed. They are careful for the development of future of their organizations which indicates their high levels of organizational commitment and association.

The results of the study have shown significant contribution towards hypotheses acceptance. We posited five hypotheses towards significant relationship between four aspects of spirituality and organizational commitment All the correlations are found positively and significantly correlated, where $H 1$ is accepted as $r=.298 p<0.01, H 2$ as $\quad r=.386$ $p<0.01, H 3$ as $r=.383 p<0.01$ and $H 4$ as $r=.154 p<0.05$. The H5 is accepted as spirituality has significant impact on organizational commitment i.e. $F(4116)=7.94 p<0.01$ as $21.5 \%$ variation is explained by spirtuality. The results of the study are quite similar to the studies conducted previously .Majority of the managers have strong inner connection with their organizations as their commitment level with their workplace is increasing day by day. Those managers are productive, satisfied and well performing more whose lives are governed according to their cognitive philosophy of life. Where as the managers with strong interpersonal and spiritual relations with their organizational employees are more significantly committed and loyal to their organizations.

The mean values of all the fours aspects of spirituality are given as 3.91, 3.35, 3.57 and 3.63 in which the mean value of intrapersonal aspect is maximum than rest of three. This indicates managers are deploying their full abilities, utilizing talents, and energy while working. Their higher levels of commitment is a result of their strong will power, determination as they face all the difficulties with courage, hope and adapt well even in the face of difficult and stressful situations. They are self motivated and motivate intrinsically their subordinates and entire working environment and act like a strong community in order to face the worst and unfavorable situations. Resultantly their productivity, behaviour at work and commitment always keeps a consistent rise. Also they keep on enhancing their level of work spirituality as they are want to find more about themselves and have devoted towards seeking more and more knowledge as a way of adjusting their attitudes, which ensures the fact that majority of the bank managers have a huge thirst of getting knowledge about themselves in order to adjust their spiritual behaviour in their respective organizations.

Majority of the managers have strong passion for what they do at work as they deploy wisdom and enthusiasm for doing good at work which is a sign of their affective job involvement. The results show that among various modes spirituality the mode of self determination has the highest scores with highest mean values $M=4.32$ and standard deviation .46.This means that the banking professionals have strong determination and motive behind their working activities and no matter how hard the circumstances they are ready and determined to face the situation. As burden of work in banks are too much and requires lot of involvement, concentration and time so the little score in partnership mode of spirituality indicates that managers don't take guidance in strengthening further their relationship with God very often. Also there is a reason that these managers are mature enough and belong to high age groups having enough knowledge of religion, so they don't want to spend more time on getting some religious guidance from any source very often. On the whole, the managers are found good in practicing spiritual values and they have a strong sense of attachment with their organizations.

\section{Managerial Inferences}

Due to the glowing and benefit oriented impact of work spirituality the policy makers and top management should orient spiritual culture in their organizations in such a way that spiritual values help in adjusting the employee's behavior and attitude by enhancing multifold commitment towards work. Employee's affiliation and attachment with 
their organizations would be stronger when they found a match between personal and organizational vsision.Orienting spiritual values in organizational culture improves communication, character and interpersonal relationships of employees by prevailing the values of affection, altruistic love and care in the organization. The orientation of newly hired employees should be done in such a way that more focus on developing ethical, moral and spiritual values should be given in order to develop sense of wholeness and organizational attachment which would resultantly generate strong commitment.

\section{Limitations and Guidelines for Future Research}

The limitations of the research should be noted that our sample belongs to financial sector of the economy, if more sectors were involved in the study the results could be more gernlizable.Also the generalizebility of the study could be achieved if multi sampling technique is used and if the data is collected on the time series basis. However the future guide lines for the study suggest that both financial and economic position of employees should also be considered for further investigation.Like the leaders, the context of spirtuality in employees and subordinates should also be investigated.

\section{References}

Aydin, B., \& Ceylan,A. (2009). The effect of spiritual leadership on organizational learning capacity, African Journal of Business Management, 3(5), 184-190.

Baldrige National Quality Program. (2005). Criteria for performance excellence. National Institute of Standards and Technology, Department of Commerce.

Barrett, R. (1998). Liberating the corporate soul, Boston: Butterworth-Heinemann.

Barrett, R. (2003). Culture and consciousness: Measuring spirituality in the workplace by mapping values. In R.A. Giacalone., \& C. L. Jurkiewicz (Eds.), Handbook of workplace spirituality and organizational performance, (pp. 345-366), New York: M. E. Sharp.

Benware, C., \& Deci, E. L. (1984). Quality of learning with an active and passive motivational set. American Educational Research Journal, 21, 755-765.

Bhindi, N., \& Duigan, P. (1997a). Authenticity in leadership: An emerging perspective. Journal of Educational Administration, 35(3), 195-209.

Bhindi, N., \& Duigan, P. (1997b). Leadership for a new century: Authenticity, intentionality, spirituality and sensibility. Educational Manegement \& Administration, 25(2), 117-132.

Brandt, E. (1996). Corporate pioneers explore spirituality, HR Magazine, 41, 82-87.

Castells, M. (1998). End of Millennium. Blackwell Publishers Ltd.

Chopra, D. (2002). The soul of leadership. School Administrator, 59(8).

Conger, J.A. (1994). Spirit at work. San Francisco, Jossey- Bass.

Deci, E. L., \& Ryan, R. M. (1985). Intrinsic motivation and self-determination in human behavior. New York:Plenum.

Dushon D., \& Plowman, D. A. (2005) Nurturing the spirit at work: Impact on unit performance. The Leadership Quarterly, 16(5), 807-834.

Eggert, N. (1998). Contemplative leadership for entrepreneurial organizations: Paradigms, metaphors, and wicked problems, Quorum Books, Greenwood Publishing Group, Inc.

Fairholm, G. (1996). Spiritual leadership: Fulfilling whole-self needs at work, Leadership \& Organization Development Journal, 17(5), 11-17.

Frew, E. J. (2000). Stressors, strain, and spirituality at work, Dissertations Abstract International, DAI-A61/04, 1506.

Fry, L. W. (2005). Toward a theory of ethical and spiritual well-being and corporate social responsibility through spiritual leadership. Forthcoming in Giacalone, R.A. and Jurkiewicz, C.L., (Eds), Positive psychology in business ethics and corporate responsibility, Greenwich, CT: Information Age Publishing.

Fry, L. W., Vitucci, S., \& Cedillo, M. (2003). Transforming the army through spiritual leadership, Unpublished manuscript, Tarleton State University-Central Texas, Killeen, TX. Available: http://www.tarleton.edu/ fry/resources.html.

Fry, L., \& Matherly, L. (2006). Workplace spirituality, spiritual leadership, and performance excellence, In S. Roglberg \& C. Reeve (Eds.), The Encyclopedia of Industrial and Organizational Psychology, San Francisco: Sage Publishing.

Hesselbein, Francis. (1997). Leading for Innovation and Organizaing for Results, Marshall Press. 
Hillard, J.C. (2004). Inspired by the Golden Rule: Business ethics titles bring religions principles into the workplace. Publishers Weekly, 21. S12.

Kaplan, R. S., \& Norton, D. P. (1992). The balanced scorecard--Measures that drive performance. Harvard Business Review, 70, 71-79.

Kaplan, R. S., \& Norton, D. P. (1996). Using the balanced scorecard as a strategic management system. Harvard Business Review, 74, 75-76.

Kaplan, R. S., \& Norton, D. P. (2004). Strategy maps: Converting intangible assets into tangible outcomes, Boston: Harvard Business School Press.

Klein, E. (2001). Values, gifts, and legacy: The keys to high performance and high fulfillment. The Journal for Quality \& Participation, 24(1), 32-33.

Klein, K. J., \& House, R. J. (1995). On fire: Charismatic leadership and levels of analysis. Leadership Quarterly, 6(2), 183-198.

Lilius, J. M., Worline, M. C., Dutton, J. E., Kanov, J., Frost, P. J., and Maitlis, S. (2005). Exploring the Contours of Compassion at Work, Working Paper Series, Centre for Positive Organizational Scholarship, Ross School of Business, Michigan USA.

Malone, P. F., \& Fry, L. W. (2003). Transforming schools through spiritual leadership: A field experiment, Paper presented at the Academy of Management, Seattle, WA.

Mario. F., Frederick, B., \& Gary. G .D. (2009). The spiritual dimension in leadership at Dilmah Tea. Leadership and Organization Development Journal, 30(6), 522-539

Meyer, J., Paunonen, S., Gellatly, I., Goffin, R., and Jackson, D. (1989). Organizational Commitment and job performance: It's the nature of the commitment that counts. Journal of Applied Psychology, 74, 152-156.

Miller, L. (1998). After their checkup for the body, some get one for the soul. The Wall Street Journal, A1, A6.

Moorman, R. H. (1993). The influence of Cognitive and Affective based Job Satisfaction Measures on the Relationship between Satisfaction and Organizational Citizenship, Behavior. Human Relations, 46, 759-776.

Power, F. C., Higgins, A., \& Kohlberg, L. (1989). Lawrence kohlberg's approach to moral education. New York: Columbia University Press.

Rinpoche, S. (1993). The tibetan book of living and dying. Harper One Publishers.

Rogers, J. L., \& Dantley. M. E. (2001). Invoking the spiritual in campus life and leadership. Journal of College Student Development, 42(6), 589-603.

Rojas, R. R. (2002). Management Theory and Spirituality: A framework and validation of the Independent Spirituality Assessment Scale. Doctoral Dissertation, University of Argosy.

Stadler, F. (1998). The Network Paradigm: Social Formation in Age of Information. Information society, (14)4.

Townsend, J. S. (1984). The development of the spiritual leadership qualities inventory. Journal of Psychology and Religion, 12, 305-313.

Vaill, P. V. (1998). Spirited leading learning: Process wisdom for a new age, San Francisco: Jossey-Bass.

Vicari, S. K. (2003). Spirituality in educational leadership, Illinois State University.

Wheatley, M. J. (1994). Leadership and the new science: Learning about organizations from an orderly universe, San Francisco: Berrett-Koehler. 
Table 1. Descriptives for aspects and relational modes of spirituality and Organizational Commitment $(N=121)$

\begin{tabular}{|c|c|c|c|c|c|c|}
\hline $\begin{array}{c}\text { Aspects of } \\
\text { Spirituality }\end{array}$ & Relational Modes of Spirituality & Min & Max & Sum & Mean & SD \\
\hline \multirow{4}{*}{} & Fulfillment of Self & 1.67 & 4.67 & 423.67 & 3.50 & .52 \\
\cline { 2 - 7 } & Self Determination & 3.00 & 5.00 & 523.33 & 4.32 & .46 \\
\cline { 2 - 7 } & Self Control & 2.00 & 5.00 & 440.33 & 3.64 & .55 \\
\cline { 2 - 7 } & Discovery of Self & 2.00 & 5.00 & 463.00 & 3.83 & .66 \\
\cline { 2 - 7 } & Enrichment of Self & 2.67 & 5.00 & 516.67 & 4.27 & .48 \\
\hline & Intrapersonal & $\mathbf{3 . 1 3}$ & $\mathbf{4 . 6 0}$ & $\mathbf{4 7 3 . 4 0}$ & 3.91 & $\mathbf{. 3 1}$ \\
\hline & Partnership Mode & 1.33 & 5.00 & 382.00 & 3.16 & .66 \\
\cline { 2 - 7 } & Small Group Mode & 1.00 & 5.00 & 428.33 & 3.54 & .87 \\
\cline { 2 - 7 } & Organizational Mode & 1.33 & 5.00 & 393.33 & 3.25 & .87 \\
\cline { 2 - 7 } & Movement Mode & 2.00 & 4.67 & 418.00 & 3.45 & .60 \\
\hline & Interpersonal & $\mathbf{1 . 9 2}$ & $\mathbf{4 . 7 5}$ & $\mathbf{4 0 5 . 4 2}$ & 3.35 & $\mathbf{. 5 4}$ \\
\hline & Ideopraxis & $\mathbf{2 . 0 0}$ & $\mathbf{4 . 6 7}$ & $\mathbf{4 3 2 . 6 7}$ & 3.57 & $\mathbf{. 5 2}$ \\
\hline & Transactional Mode & 2.33 & 5.00 & 462.00 & 3.82 & .54 \\
\cline { 2 - 7 } & Transformational Mode & 2.00 & 4.67 & 436.67 & 3.61 & .62 \\
\cline { 2 - 7 } & Transfiguration Mode & 2.00 & 5.00 & 418.00 & 3.45 & .66 \\
\hline & Suprapersonal & $\mathbf{2 . 6 7}$ & $\mathbf{4 . 5 6}$ & $\mathbf{4 3 8 . 8 9}$ & $\mathbf{3 . 6 3}$ & $\mathbf{. 4 0}$ \\
\hline
\end{tabular}

Table 2. Pearson’s Correlation among aspects of Spirituality and Organizational Commitment $(N=121)$

\begin{tabular}{|l|c|c|c|c|}
\hline \multicolumn{1}{|c|}{ Variable } & $\mathbf{1}$ & $\mathbf{2}$ & $\mathbf{3}$ & $\mathbf{4}$ \\
\hline Intrapersonal Aspects & & & & \\
\hline Interpersonal Aspects & $.503(* *)$ & & & \\
\hline Suprapersonal & $.389\left(^{* *}\right)$ & $.408(* *)$ & & \\
\hline Ideopraxis & $.348(* *)$ & $.251\left(^{* *}\right)$ & $.395(* *)$ & .154 \\
\hline Organizational Commitment & $.298(* *)$ & $.386\left(^{* *}\right)$ & $.383(* *)$ & \\
\hline
\end{tabular}

*. Correlation is significant at the 0.05 level (2-tailed).

**. Correlation is significant at the 0.01 level (2-tailed).

Table 3. ANOVA ${ }^{\mathrm{b}}$

\begin{tabular}{|c|c|c|c|c|c|c|}
\hline \multicolumn{2}{|l|}{ Model } & Sum of Squares & df & Mean Square & F & Sig. \\
\hline & Regression & 415.677 & 4 & 103.919 & 7.946 & $.000^{\mathrm{a}}$ \\
\hline & Residual & 1517.100 & 116 & 13.078 & & \\
\hline & Total & 1932.777 & 120 & & & \\
\hline
\end{tabular}


Table 4. Regression Model

\begin{tabular}{|c|c|c|c|c|c|c|c|c|c|}
\hline \multirow[b]{2}{*}{ Model } & \multirow[b]{2}{*}{$\mathrm{R}$} & \multirow{2}{*}{$\begin{array}{c}\mathrm{R} \\
\text { Square }\end{array}$} & \multirow{2}{*}{$\begin{array}{c}\text { Adjusted R } \\
\text { Square }\end{array}$} & \multirow{2}{*}{$\begin{array}{l}\text { Std. Error of the } \\
\text { Estimate }\end{array}$} & \multicolumn{5}{|c|}{ Change Statistics } \\
\hline & & & & & R Square Change & F Change & df1 & df2 & Sig. F Change \\
\hline 1 & $.464^{\mathrm{a}}$ & .215 & .188 & 3.61641 & .215 & 7.946 & 4 & 116 & .000 \\
\hline
\end{tabular}

Table 5. Coefficients ${ }^{\mathrm{a}}$

\begin{tabular}{|c|c|c|c|c|c|c|c|}
\hline \multirow[b]{2}{*}{ Model } & \multicolumn{2}{|c|}{ Unstandardized Coefficients } & \multirow{2}{*}{$\begin{array}{c}\begin{array}{c}\text { Standardized } \\
\text { Coefficients }\end{array} \\
\text { Beta }\end{array}$} & \multirow[b]{2}{*}{$\mathrm{t}$} & \multirow[b]{2}{*}{ Sig. } & \multicolumn{2}{|c|}{ 95\% Confidence Interval for B } \\
\hline & $\mathrm{B}$ & Std. Error & & & & Lower Bound & Upper Bound \\
\hline (Constant) & 4.678 & 4.459 & & 1.049 & .296 & -4.154 & 13.509 \\
\hline $\begin{array}{l}\text { Intrapersonal } \\
\text { Aspects }\end{array}$ & .074 & .086 & .086 & .862 & .391 & -.096 & .243 \\
\hline $\begin{array}{l}\text { Interpersonal } \\
\text { Aspects }\end{array}$ & .152 & .061 & .244 & 2.472 & .015 & .030 & .273 \\
\hline Suprapersonal & .297 & .108 & .266 & 2.750 & .007 & .083 & .511 \\
\hline Ideopraxis & -.107 & .234 & -.042 & -.456 & .649 & -.571 & .357 \\
\hline
\end{tabular}

